\title{
Satisfaction with health care system: A comparative study between market-based insurance model of the United States and "out-of-pocket" model in developing and low-income countries
}

\author{
Ram Lakhan*1, Sean Y. Gillette ${ }^{2}$, Sean Lee ${ }^{3}$, Manoj Sharma ${ }^{4}$ \\ ${ }^{1}$ Department of Health and Human Performance, Berea College, Berea, Kentucky, USA \\ ${ }^{2}$ Department of Chemistry, Berea College, Berea, Kentucky, USA \\ ${ }^{3}$ Department of Music, Berea College, Berea, Kentucky, USA \\ ${ }^{4}$ Behavior and Environmental Health, School of Public Health, Jackson State University, Jackson, Mississippi, USA
}

Received: December 29, 2019

DOI: $10.5430 /$ ijh.v6n1p41
Accepted: February 17, 2020

Online Published: February 24, 2020

\begin{abstract}
Background and purpose: Access to healthcare services is an essential component for ensuring the quality of life. Globally, there is inequity and disparities regarding access to health care. To meet the global healthcare needs, different models of healthcare have been adopted around the world. However, all healthcare models have some strengths and weaknesses. The purpose of this study was to examine the satisfaction among a group of undergraduate students from different countries with their health care models namely, insurance-based model in the United States and "out-of-pocket" model prevalent in low-income countries.

Methods and materials: The study utilized a cross-sectional research design. Undergraduate students, representing different nationalities from a private Southeastern College, were administered a researcher-designed 14-item self-reported electronic questionnaire. Independent $t$-test and $\chi^{2}$ statistics were used to examine the differences between two health care systems and the qualitative responses were analyzed thematically.

Results: Satisfaction towards health care system between the United States and low-income countries was found significantly different $(p<.05)$. However, students in both settings experienced an inability toward affording quality healthcare due to economic factors and disparities.

Conclusions: There is dissatisfaction with health care both in the United States and low-income developing countries among a sample of undergraduate students representing these countries. Efforts to ensure low-cost affordable health care should be a global goal.
\end{abstract}

Key Words: Health care system, Global health, USA

\section{INTRODUCTION}

Health care services are needed by everyone at some point in time in their life. Every nation attempts to provide health care to its citizens. Different models of health care systems are being followed across the world to meet people's health care needs. ${ }^{[1]}$ Depending on the economy and other social

\footnotetext{
*Correspondence: Ram Lakhan; Email: ramlakhan15@gmail.com; Address: Department of Health and Human Performance, Berea College, Berea, Kentucky 40404, USA.
} 
and political factors, nations have either developed their own system of providing health care or they have adopted it from other countries. Broadly speaking, two types of health care systems are followed in the world: Bismarck and Beveridge. Bismarck is a decentralized health care system that was developed towards the end of $19^{\text {th }}$ century by Bismarck in newly-unified Germany. ${ }^{[2,3]}$ Beveridge is a centralized health care model that was established in 1948 by Lord Beveridge in the $\mathrm{UK}^{[3]}$

Bismarck model uses an insurance system. It is funded jointly by the employer and employee through payroll deduction. Insurers are called "sickness funds." In this type of system, everyone is covered and the healthcare industry does not make a profit, though the doctors and hospitals tend to be private in this model. Currently, this model is being followed in Germany, France, Belgium, Luxembourg, the Netherlands, Japan, Switzerland, and to some extent in some Latin American countries. Previously, Greece, Italy, Portugal, Spain, and South Korea also followed the Bismarck model. Between the years 1970 and 1980, they shifted to the Beveridge model. ${ }^{[3,4]}$ The Beveridge model is also termed as the National Health System in which health care is provided and funded by the government through tax payments. ${ }^{[3,4]}$ Clinics and hospitals are owned by the government. Most doctors are government employees, however, there are private practitioners too but the private doctors submit their bills to the government, not to their clients, and the government decides what they would be paid for what services. ${ }^{[3,4]}$ This model is being followed in Great Britain, Spain, Ireland, Denmark, Sweden, Finland, Iceland, most of Scandinavia, Hong Kong, Australia, and New Zealand. Cuba is considered the purest example of this model.

The "out-of-pocket" is considered the third model which is basically a mixed form of Bismarck, Beveridge, and a heavy component of self-pay. Mostly developing and lowincome countries follow this model. ${ }^{[5]}$ The United States has developed a market-based mixed model which is supported through insurance. It comprises elements of all three health care models that exist in the world including Bismarck, Beveridge, and "out-of-pocket."

On prima facie, it appears that the United States health care system is the best in the world as it comprises several elements of all other models in addressing the health needs of its citizens. Low-income and developing countries are struggling with several social and political issues. Inferior governmental structure, chronic poverty, unemployment, poor education and awareness, lack of professionals, inadequate infrastructure, and many cultural and societal views and practices affect health care. The insurance-based mixed model in the United States might have evolved by examining the strengths and weaknesses of preexisting models, Bismarck and Beveridge while developing and low-income nations' "out-of-pocket" model might have emerged as a result of poorer government and lack of resources. What people think and feel about two models, mixed and "out-of-pocket," is a great research question that can identify major gaps in the health care system and highlight areas of improving health care delivery. When it comes to satisfaction with health care system, three aspects are main concerns to the people. These are its accessibility, affordability, and quality. It is this context that the purpose of this study was to examine the satisfaction among a group of undergraduate students from different countries with their health care models namely, insurancebased model in the United States and "out-of-pocket" model prevalent in low-income countries.

\section{METHODS AND MATERIALS}

The study utilized a cross-sectional research design. The study was approved by the Institutional Review Board of the College (Protocol \# 303). All participants completed a written consent before taking the survey. Data were collected online by emailing a Qualtrics link to all students at a private Southeastern College in the United States in the month of April, 2019. Two follow up reminders were given. A 14-item questionnaire was prepared by the lead researcher and reviewed by 17 students enrolled in a Global Health Seminar Course in the college before finalizing it. The first five questions in part one were sociodemographic and seven in part two were designed to ask participants' views on the health care system in the country where they have lived at least for five years. Seven questions asked in part two were: i) Does your economic condition affect the affordability of health services in your country? ii) Does your economic condition affect the quality of health services? iii) Does your economic condition affect the accessibility of health services? iv) Do you feel satisfied with the quality of healthcare in responding to all health conditions in your nation? v) Do you receive timely access to health care services in your nation regardless of your medical condition (minor or major) and location? vi) List three of the best and three of the worst aspects of the healthcare system of your country of residence and vii) circle term from the given list that they think describe the health care system best in their own countries. These terms were: Qualified Professionals, Readily Available, Affordable, Poorly Equipped, Weak Policies, Adaptive, Flexible, Developed, Expensive, Racist, Efficient, Costly, Complicated, Painful, Wide Variety, Quality, Innovative, Not Accessible, Privatized, Minimal, and Expensive Insurance. Questions from one through five in part two were used as 
Likert scale with the following options for question number one to three: definitely yes, probably yes, might or might not, probably not, and definitely yes and in reverse order for item number four to five.

\section{Data analysis}

Other than the United States, all participants who specified the name of their country were found to be belonging to the "out-of-pocket" health care system. Thus, they were grouped as one category as "all others." Question one to three of part two asked if their affordability, accessibility, and quality is affected on the basis of the economic condition were added together and one continuous variable of the total was obtained. Country of residence (United States vs all others) was used as the categorical independent variable. For item number four and five the outcome variable were dichotomized by adding definitely yes, and probably yes as one (yes) and definitely no and probably no as a zero (no). Might or might not were divided by two and added half to each option of yes and no. Independent $t$-test was used to examine the difference between a total of affordability, accessibility, and quality in reference to economic condition with mixed (United States) and out-of-pocket (all others) and analysis of variance was used to see this difference with socioeconomic conditions. The $\chi^{2}$ statistics was used to examine the difference in satisfaction with the quality of health care and timely accesses regardless of the condition and location between two health care models (United States vs. all others). The descriptive statistics (e.g., frequencies and percentages) were used to describe the characteristics of the participants. The responses listed as three best and three worst features of the health care system were analyzed and presented in a qualitative manner with frequencies and percentages.

\section{RESUlts}

A total of 108 participants filled out the survey. Of these, $60(55.6 \%)$ participants identified as United States residents, $26(24.1 \%)$ from other countries, and $22(20.4 \%)$ did not specify their country of residence. In "all other" category participants have identified them from India 3 (2.8\%), Turkmenistan 2 (1.9\%), Venezuela 2 (1.9\%), and Azerbaijan, China, Malaysia, Ecuador, Guatemala, Honduras, Indonesia, Iran, Kenya, Sri Lanka, Taiwan, Tanzania, and Zambia each $1(0.9 \%)$. Total $5(4.5 \%)$ participants identified them either as Asian or African (see Table 1).

The $t$-test result indicated that satisfaction in affordability, accessibility, and quality with the economic condition of the people was found different between the United States and other countries (see Tables $2 \& 3$ ). While satisfaction with the quality of healthcare in responding to all health conditions and timely access in receiving health care regardless of medical condition and location did not differ between the United States and other countries (see Table 4).

Table 1. Characteristics of the participants

\begin{tabular}{|c|c|c|c|}
\hline Category & & $\mathbf{n}$ & $\%$ \\
\hline \multirow{4}{*}{ Gender } & Female & 70 & 64.8 \\
\hline & Male & 36 & 33.3 \\
\hline & Did not tell gender & 2 & 1.9 \\
\hline & Total & 108 & 100.0 \\
\hline \multirow{6}{*}{ Age group } & 18 to 24 years old & 100 & 92.6 \\
\hline & 25 to 29 years old & 3 & 2.8 \\
\hline & 30 to 34 years old & 2 & 1.9 \\
\hline & 35 to 40 years old & 2 & 1.9 \\
\hline & Unspecified & 2 & 1.9 \\
\hline & Total & 108 & 100.0 \\
\hline \multirow{4}{*}{$\begin{array}{l}\text { Socioeconomic } \\
\text { status }\end{array}$} & Lower Class & 46 & 42.6 \\
\hline & Lower Middle Class & 45 & 41.7 \\
\hline & Upper Middle Class & 16 & 14.8 \\
\hline & Total & 107 & 99.1 \\
\hline \multirow{20}{*}{ Country } & Azerbaijan & 1 & 0.9 \\
\hline & China & 1 & 0.9 \\
\hline & Malaysia & 1 & 0.9 \\
\hline & Ecuador & 1 & 0.9 \\
\hline & Greece & 1 & 0.9 \\
\hline & Guatemala & 1 & 0.9 \\
\hline & Honduras & 1 & 0.9 \\
\hline & India & 3 & 2.8 \\
\hline & Indonesia & 1 & 0.9 \\
\hline & International (Asia and Africa) & 5 & 4.6 \\
\hline & Iran & 1 & 0.9 \\
\hline & Kenya & 1 & 0.9 \\
\hline & Sri Lanka & 1 & 0.9 \\
\hline & Taiwan & 1 & 0.9 \\
\hline & Tanzania & 1 & 0.9 \\
\hline & Turkmenistan & 2 & 1.9 \\
\hline & United States & 60 & 55.6 \\
\hline & Venezuela & 2 & 1.9 \\
\hline & Zambia & 1 & 0.9 \\
\hline & Total & 108 & 100.0 \\
\hline
\end{tabular}

Examining the best aspects of health care system in all other countries, $16(61.53 \%)$ reported their health care system to be free, $5(19.23 \%)$ reported it as cheap or really inexpensive and also available to everyone, $4(15.38 \%)$ reported having very good professionals, and $3(11.53 \%)$ stated that they had good quality health care services. About $5(15.38 \%)$ considered that health care services were better if one was living in cities and went to private hospitals and clinics. 
Table 2. Does economic condition affects affordability, accessibility and quality and do people feel satisfied and receives timely access

\begin{tabular}{|c|c|c|c|c|c|c|c|}
\hline \multirow{2}{*}{\multicolumn{2}{|c|}{ Affordability, accessibility, and quality }} & \multicolumn{2}{|c|}{ Unspecified } & \multicolumn{2}{|c|}{ All others } & \multicolumn{2}{|c|}{ United States } \\
\hline & & \multirow{2}{*}{$\begin{array}{l}\mathbf{n} \\
8\end{array}$} & \multirow{2}{*}{$\begin{array}{l}\% \\
36.4 \%\end{array}$} & \multirow{2}{*}{$\frac{\mathbf{n}}{7}$} & \multirow{2}{*}{$\begin{array}{l}\% \\
26.9 \%\end{array}$} & \multirow{2}{*}{$\begin{array}{l}\mathbf{n} \\
31\end{array}$} & \multirow{2}{*}{$\begin{array}{l}\% \\
51.7 \% \\
\end{array}$} \\
\hline \multirow{5}{*}{ Affect affordability } & Definitely yes & & & & & & \\
\hline & Probably yes & 3 & $13.6 \%$ & 2 & $7.7 \%$ & 8 & $13.3 \%$ \\
\hline & Might or might not & 3 & $13.6 \%$ & 5 & $19.2 \%$ & 4 & $6.7 \%$ \\
\hline & Probably not & 2 & $9.1 \%$ & 3 & $11.5 \%$ & 3 & $5.0 \%$ \\
\hline & Definitely not & 1 & $4.5 \%$ & 2 & $7.7 \%$ & 0 & $0.0 \%$ \\
\hline \multirow{5}{*}{ Affect quality } & Definitely yes & 4 & $18.2 \%$ & 11 & $42.3 \%$ & 23 & $38.3 \%$ \\
\hline & Probably yes & 4 & $18.2 \%$ & 2 & $7.7 \%$ & 12 & $20.0 \%$ \\
\hline & Might or might not & 8 & $36.4 \%$ & 2 & $7.7 \%$ & 8 & $13.3 \%$ \\
\hline & Probably not & 1 & $4.5 \%$ & 3 & $11.5 \%$ & 3 & $5.0 \%$ \\
\hline & Definitely not & 0 & $0.0 \%$ & 1 & $3.8 \%$ & 0 & $0.0 \%$ \\
\hline \multirow{5}{*}{ Affect accessibility } & Definitely yes & 7 & $31.8 \%$ & 9 & $34.6 \%$ & 27 & $45.0 \%$ \\
\hline & Probably yes & 4 & $18.2 \%$ & 3 & $11.5 \%$ & 10 & $16.7 \%$ \\
\hline & Might or might not & 3 & $13.6 \%$ & 3 & $11.5 \%$ & 4 & $6.7 \%$ \\
\hline & Probably not & 3 & $13.6 \%$ & 3 & $11.5 \%$ & 5 & $8.3 \%$ \\
\hline & Definitely not & 0 & $0.0 \%$ & 1 & $3.8 \%$ & 0 & $0.0 \%$ \\
\hline \multicolumn{8}{|l|}{ Satisfaction and timely access } \\
\hline \multirow{5}{*}{$\begin{array}{l}\text { Do you feel satisfied with the } \\
\text { quality of healthcare in } \\
\text { responding to all health } \\
\text { conditions in your nation? }\end{array}$} & Definitely not & 4 & $23.5 \%$ & 5 & $26.3 \%$ & 15 & $32.6 \%$ \\
\hline & Probably not & 7 & $41.2 \%$ & 2 & $10.5 \%$ & 13 & $28.3 \%$ \\
\hline & Might or might not & 2 & $11.8 \%$ & 6 & $31.6 \%$ & 10 & $21.7 \%$ \\
\hline & Probably yes & 3 & $17.6 \%$ & 6 & $31.6 \%$ & 4 & $8.7 \%$ \\
\hline & Definitely yes & 1 & $5.9 \%$ & 0 & $0.0 \%$ & 4 & $8.7 \%$ \\
\hline \multirow{5}{*}{$\begin{array}{l}\text { Do you receive timely access to } \\
\text { health care services in your } \\
\text { nation regardless of your } \\
\text { medical condition (minor or } \\
\text { major) and location? }\end{array}$} & Definitely not & 1 & $5.9 \%$ & 4 & $21.1 \%$ & 10 & $21.7 \%$ \\
\hline & Probably not & 4 & $23.5 \%$ & 2 & $10.5 \%$ & 9 & $19.6 \%$ \\
\hline & Might or might not & 4 & $23.5 \%$ & 5 & $26.3 \%$ & 13 & $28.3 \%$ \\
\hline & Probably yes & 7 & $41.2 \%$ & 8 & $42.1 \%$ & 9 & $19.6 \%$ \\
\hline & Definitely yes & 1 & $5.9 \%$ & 0 & $0.0 \%$ & 5 & $10.9 \%$ \\
\hline
\end{tabular}

Table 3. Difference in affordability, accessibility, and quality between United States vs. other countries and with socioeconomic status

\begin{tabular}{|c|c|c|c|c|c|}
\hline \multirow{2}{*}{ Affordability, accessibility, and quality } & \multirow{2}{*}{ United States vs. Others and SES } & \multicolumn{2}{|c|}{ Measures } & \multirow{2}{*}{$t$-value } & \multirow{2}{*}{$p$-value } \\
\hline & & Mean & SD & & \\
\hline \multirow{2}{*}{ United States vs. others } & All others & 3.68 & 3.94 & \multirow{2}{*}{1.96} & \multirow{2}{*}{.053} \\
\hline & United States & 2.07 & 2.55 & & \\
\hline \multirow{3}{*}{ Socioeconomic status } & Lower Class & 2.41 & 2.87 & \multirow{3}{*}{.720} & \multirow{3}{*}{.490} \\
\hline & Lower Middle Class & 3.18 & 3.16 & & \\
\hline & Upper Middle Class & 2.22 & 3.42 & & \\
\hline
\end{tabular}


Table 4. Difference in satisfaction with quality and timely access United States vs. other countries

\begin{tabular}{|c|c|c|c|c|c|c|c|}
\hline \multirow{3}{*}{ Category } & \multirow{3}{*}{ Response } & \multicolumn{4}{|c|}{ Country } & \multirow{3}{*}{$\chi^{2}$} & \multirow{3}{*}{$p$-value } \\
\hline & & \multicolumn{2}{|c|}{ All others } & \multicolumn{2}{|c|}{ USA } & & \\
\hline & & $\mathbf{n}$ & $\%$ & $\mathrm{n}$ & $\%$ & & \\
\hline \multirow{2}{*}{$\begin{array}{l}\text { Do you feel satisfied with the quality of } \\
\text { healthcare in responding to all health conditions } \\
\text { in your nation? }\end{array}$} & No & 12 & $63.2 \%$ & 31 & $67.4 \%$ & \multirow[b]{2}{*}{1.02} & \multirow[b]{2}{*}{.60} \\
\hline & Yes & 7 & $36.8 \%$ & 15 & $32.6 \%$ & & \\
\hline \multirow{2}{*}{$\begin{array}{l}\text { Do you receive timely access to health care } \\
\text { services in your nation regardless of your medical } \\
\text { condition (minor or major) and location? }\end{array}$} & No & 8 & $42.1 \%$ & 26 & $56.5 \%$ & \multirow[b]{2}{*}{3.27} & \multirow[b]{2}{*}{.19} \\
\hline & Yes & 11 & $57.9 \%$ & 20 & $43.5 \%$ & & \\
\hline
\end{tabular}

In the United States, mainly following best qualities of the healthcare system were found. All types of medications are available for $5(8.33 \%)$, good insurance that can help people to get good healthcare is available for 5 (8.33\%), healthcare services are provided by highest trained professionals $4(6.66 \%)$ and $4(6.66 \%)$ can receive healthcare with the Medicaid. Two (3.33\%) were happy that healthcare was available even in smaller places. One $(1.66 \%)$ considered the best quality of American health care system was that it is comprehensive, great nursing staff, many employers provide insurance, most doctors really want to help, variety of specializations are available, it is safe and regulated well, and timely access with 911 .

When it comes to the deficits of the health care system, in all other countries, it was found that 6 reported $(19.23 \%)$ public hospitals lacked proper infrastructure, 4 (15.38\%) reported having poor facilities in rural areas, and $3(11.53 \%)$ reported experiencing corruption. Commenting on infrastructure, one participant said that "women have had to have their babies on the floor, while the doctors use the flashlight from their phones." Another participant stated that "Government is unable to implement health care system the way it is planned, corruption at all levels in the health care system and privatization is taking out health care services out of reach." Two $(7.69 \%)$ reported that services were provided by the lower level of professionals and $2(7.69 \%)$ mentioned that the health care system is underfunded and medical professionals are paid very poorly. One (3.84\%) respondent reported that people with more money could get better health care in private setup. One $(3.84 \%)$ respondent said that there is huge focus on privatization. People living in rural areas are treated poorly than urban citizens. The socioeconomic position affects the quality of care. It is believed by $3.84 \%$ respondents that medicine cost is very high, people can't get health care if they are unemployed, and government employee take bribe for providing health care services specially in poorer rural areas.

United States health care system was viewed as being very expensive for the majority of the participants 15 (25.00\%). Insurance and overall health care were found very expensive and unaffordable for 7 (11.66\%) participants. One participant said that health care is "expensive, limited access for those in poverty, and medical emergencies can bankrupt a person." Another person said that "Healthcare is so expensive that, even if you have insurance, you'll probably need to set up a fund-raiser and ask for donations if you have a medical emergency." Insurance is also very complex and confusing for $4(6.63 \%)$ participants. About $8(13.33 \%)$ participants saw discrimination in the American health care system. Availability for health care services varied with the region for $3(5.00 \%)$ participants while $2(3.33 \%)$ viewed no focus on prevention and same amount of participants thought that doctors did not educate clients, therefore, there was a large communication gap. A statement by another participant "lack of preventive health care, lack of rural health care, stigma toward people with low SES, lack of cultural competence, lack of communication between doctors and patients meaning that doctors don't care how patients get sick, they just give them medicine" explains gaps further in service delivery. Health care is not available for everyone, there is lack of insurance, insurance is worst part of the health care system, patients remain untreated for a long time, there is enormously long wait times to see a specialist, and quality of care depends on socioeconomic and racial/ethnic standing were viewed by one participant.

\section{Discussion}

Our findings suggest that health care services are freely available in several nations which follow the "out-of-pocket" model but huge gap exists with access for the people who are poor and also the quality of services are extremely low due to many factors including corruption, poor technology, lack of trained professionals, poor staffing, and unequal distribution of health facilities with geographical regions. ${ }^{[6-10]}$ In comparison to the "out-of-pocket "model, citizens in the United States enjoy high quality of health care services with the availability of advanced technology and specialized pro- 
fessionals without much differences with the location where they live unlike the developing nations but in comparison to other industrialized nations such as Canada and Germany, the United States spends highest amount of money on health but still, satisfaction outcome are poorer. ${ }^{[2,11]}$ However, when it comes to the affordability of health services in the United States, people do have the options depending on the class to which they belong, ${ }^{[2]}$ otherwise, it is viewed highly expensive and unaffordable. ${ }^{[12]}$ People in the United States experience huge disparities in availing health care services and also with health outcomes ${ }^{[13-15]}$ which can be comparable to the people in low-income and developing nations who experience widespread disparities in healthcare. ${ }^{[16-24]}$

Findings of this study are very helpful in understanding factors of dissatisfaction with healthcare models in several countries. However, there is very limited research on this subject, which limits us in comparing findings of this research. Our findings are slightly comparable with Deaton (2008) research, which reported higher healthcare satisfaction with higher per capita income. ${ }^{[25]}$

In conclusion, it can be said that there is dissatisfaction with health care both in the United States and low-income developing countries among a sample of undergraduate students representing these countries. Efforts to ensure low-cost affordable health care should be the goal all over the world.

\section{Strengths and limitations}

The findings of this study are useful in understanding wider gaps between two health care systems. However, this study also has few limitations. First, the study utilized a crosssectional design which cannot ascertain the temporality of associations. Second, the study relied on self-reports which are amenable to acquiescence bias, dishonesty, extreme response bias, etc. Third, the sample for this study was drawn from a private South Eastern college which is in an interracial, tuition promise institute that admits people across the world who are economically disadvantaged and unable to pursue higher education at other institutions due to their paying inability. Thus the population was surveyed belonged to lower socioeconomic status in reference to their countries. Hence, the satisfaction level with the socioeconomic status could not be examined. In future studies, participants should be recruited from all socioeconomic strata from more countries and a large sample should be used for the analysis.

\section{CONFlicts OF InTEREST Disclosure}

The authors declare no conflicts of interest.

\section{REFERENCES}

[1] Lameire N, Joffe P, Wiedemann M. Healthcare systems - an international review: an overview. Nephrology Dialysis Transplantation. 1999; 14(suppl_6): 3-9. PMid:10528706. https ://doi.org/10.1 093/ndt/14.suppl_6.3

[2] Ridic G, Gleason S, Ridic O. Comparisons of health care systems in the United States, Germany and Canada. Materia Socio-medica. 2012; 24(2):112. PMid:23678317. https://doi.org/10.5455/ msm. 2012.24.112-120

[3] Minor L. Bishmarck, Beveridge and the "Blues". Retrieved from John Hopkins Universitywebsite (accessed Dec 28, 2019), 2010 Available from: http://web.jhu.edu/administration/provo st/docs/101014\%20Minor\%20Speech\%20PP.pdf

[4] PNHP (Physicians for National Health Program) (accessed Dec 28, 2019). Available from: https://pnhp.org/resource/health - care-systems-four-basic-models/

[5] Zaman SB, Hossain N. Universal Health Coverage: A burning need for developing countries. Journal of Medical Research and Innovation. 2017; 1(1): 18-20. https://doi.org/10.15419/jmri.41

[6] Strasser R, Kam SM, Regalado SM. Rural health care access and policy in developing countries. Annual Review of Public Health. 2016; 37: 395-412. PMid:26735432. https ://doi .org/10.1146/annu rev-publhealth-032315-021507

[7] Balarajan, Selvaraj S, Subramanian S. Health care and equity in India The Lancet. 2011; 377(9764): 505-515. https://doi .org/10.1 016/S0140-6736(10)61894-6

[8] O'Donnell O. Access to health care in developing countries: breaking down demand side barriers. Cadernos de Saude Publica. 2007; 23:
2820-2834. PMid:18157324. https ://doi.org/10.1590/S010 2-311X2007001200003

[9] Banerjee A, Deaton A, Duflo E. Wealth, health, and health services in rural Rajasthan. American Economic Review. 2004; 94(2): 326-330. PMid:19305517. https ://doi.org/10.1257/00028280413019 02

[10] Rahman SU, Smith DK. Use of location-allocation models in health service development planning in developing nations. European Journal of Operational Research. 2000; 123 (6): 437-452. https://doi .org/10.1016/S0377-2217(99)00289-1

[11] Squires DA. Explaining high health care spending in the United States: an international comparison of supply, utilization, prices, and quality. Issue brief (Commonwealth Fund). 2012; 10: 1-14.

[12] Dickman SL, Himmelstein DU, Woolhandler S. Inequality and the health-care system in the USA. The Lancet. 2017; 389(10077): 14311441. https://doi.org/10.1016/S0140-6736 (17)30398-7

[13] Braveman PA, Cubbin C, Egerter S, et al. Socioeconomic disparities in health in the United States: what the patterns tell us. American Journal of Public Health. 2010; 100(S1): S186-S196. PMid:20147693. https ://doi.org/10.2105/AJPH. 2009.166082

[14] Lasser KE, Himmelstein DU, Woolhandler S. Access to care, health status, and health disparities in the United States and Canada: results of a cross-national population-based survey. American Journal of Public Health. 2006; 96(7): 1300-1307. PMid:16735628. https://doi.org/10.2105/AJPH. 2004.059402

[15] Nelson A. Unequal treatment: confronting racial and ethnic disparities in health care. Journal of the National Medical Association. 2002; 94(8): 666-668. 
[16] Atun R, De Andrade LOM, Almeida G, et al. Health-system reform and universal health coverage in Latin America. The Lancet. 2015; 385(9974): 1230-1247. https://doi.org/10.1016/S0140-673 6(14) 61646-9

[17] Malhotra C, Do YK. Socio-economic disparities in health system responsiveness in India. Health Policy and Planning. 2012; 28(2): 197-205. PMid:22709921. https://doi.org/10.1093/heapol /czs051

[18] Kiadaliri AA, Najafi B, Haghparast-Bidgoli H. Geographic distribution of need and access to health care in rural population: an ecological study in Iran. International Journal for Equity in Health. 2011; 10(1): 39. PMid:21939511. https://doi.org/10.1186/ 1475-9276-10-39

[19] Habibov NN. On the socio-economic determinants of antenatal care utilization in Azerbaijan: evidence and policy implications for reforms. Health Economics, Policy and Law. 2011; 6(2): 175-203. PMid:20598213. https://doi .org/10.1017/S1744133110000 174

[20] Fang H, Chen J, Rizzo JA. Explaining urban-rural health disparities in China. Medical Care. 2009; 47 (12): 1209-1216. PMid:19786910. https://doi.org/10.1097/MLR.0b013e3181adcc32
[21] Wirth M, Sacks E, Delamonica E, et al. "Delivering" on the MDGs? equity and maternal health in Ghana, Ethiopia and Kenya. East African Journal of Public Health. 2008; 5(3): 133-141. https: //doi.org/10.4314/eajph.v5i3.38991

[22] Lander LR, Marshalek P, Yitayew M, et al. Rural healthcare disparities: challenges and solutions for the pregnant opioid-dependent population. West Virginia Medical Journal. 2013; 109(4): 22-28.

[23] Shayo EH, Senkoro KP, Momburi R, et al. Access and utilisation of healthcare services in rural Tanzania: a comparison of public and non-public facilities using quality, equity, and trust dimensions. Global Public Health. 2016; 11(4): 407-422. PMid:26883021. https://doi.org/10.1080/17441692.2015.1132750

[24] Nemati R, Seyedin H, Nemati A, et al. An analysis of disparities in access to health care in Iran: evidence from Lorestan province. Global Journal of Health Science. 2014; 6(5): 81-86. PMid:25168991. https://doi.org/10.5539/gjhs.v6n5p81

[25] Deaton A. Income, health, and well-being around the world: Evidence from the Gallup World Poll. Journal of Economic perspectives. 2008; 22(2): 53-72. PMid:19436768. https://doi.org/10.125 $7 /$ jep.22.2.53 